\title{
Rethinking Strategies and Programs to Improve Physical and Emotional Well-being Among Healthcare Professionals: Facing the New Normalcy
}

\author{
Claudia Gómez ${ }^{1} \cdot$ Aura Lamas $^{2} \cdot$ Flor Rocio Ramirez-Martinez ${ }^{1} \cdot$ Dan Blunk $^{3} \cdot$ Marie Leiner $^{2}$ (D) \\ Accepted: 10 January 2021 / Published online: 24 February 2021 \\ (C) International Association of Medical Science Educators 2021
}

\begin{abstract}
Background With the advent of coronavirus disease 2019 (COVID-19), a different perspective on the future of humanity has emerged that emphasizes the importance of building the capacities of healthcare providers in order to assist them with the heavy burden that these changes have placed on them both now and in the future. A reduction in the quality of life and the presence of prolonged fatigue are some of the most imminent problems that emerge among these professionals.

Objective The aim of this study was to determine the effectiveness of a holistic intervention (workshop) for health science students aimed at developing skills that will enable them to obtain a better self-assessment of their quality of life, and prolonged fatigue.

Methods Pre- and post-measures of quality of life, and prolonged fatigue were obtained from 130 health science students, including a group of 96 attendees (cases) of a 4-h wellness workshop and 34 students who did not attend (controls).

Results Paired $t$ tests indicated a significant improvement in nearly all dimensions related to quality of life, and prolonged fatigue in the case group who attended the workshop.

Conclusions A comprehensive wellness strategy that utilizes a holistic approach can play an important role in improving and promoting essential skills to improve healthcare provider's self-assessment about the quality of life and reduce their prolonged fatigue. The critical importance of these needs has long been recognized, and this will also be crucial for addressing new challenges and emerging realities.
\end{abstract}

Keywords Indivisible Self $\cdot$ Wellness $\cdot$ Healthcare personnel $\cdot$ Burnout $\cdot$ Depression

\section{Introduction}

The emergence of coronavirus disease 2019 (COVID-19) may not be the only time that humans are forced into confinement or death, as future and uncertain pandemics seem to be triggered by different factors that are complex and difficult to resolve quickly $[1,2]$. Some scientists believe that mankind's "promiscuous treatment of nature" will result in more deadly pandemics like COVID-19 because of the link between

Marie Leiner

marie.leiner@ttuhsc.edu

1 Universidad Autonoma de Ciudad Juarez, Chihuahua, Mexico

2 Department of Pediatrics, Texas Tech University Health Science Center El Paso, El Paso, TX, USA

3 Paul L. Foster School of Medicine, Texas Tech University Health Science Center El Paso, El Paso, TX, USA viruses, wildlife, and habitat destruction [3]. Healthcare providers will continually encounter challenges when providing services to others, and they will be constantly at risk and remain society's only and most effective survival resource. This unprecedented situation forced us to consider reinforcing previously recognized and unrecognized demands placed on healthcare providers during their years of training $[4,5]$. Examples of demands that require reinforcement include safety and precautionary measures aimed to reduce the probability of infection, the use of technologies, such as virtual consultations or telemedicine, the use of virtual reality, the monitoring of disease patterns to function as a part of epidemiological surveillance systems, and the enhancement of intensive training in public health and epidemiology $[6,7]$. On the other hand, it will also be necessary to invest in the development of social and emotional competencies that allow healthcare providers to care for themselves and the patients they serve $[8,9]$. The wellness of healthcare providers has historically been a source of concern. There is significant interest in 
developing programs that strengthen the capacity of these individuals to meet the demands and challenges associated with their profession [10]. Well-being and wellness are used interchangeably to describe the desired state that humans must achieve to have a good life [11-13]. Well-being involves both an objective approach (e.g., income, housing, and access to services) and a subjective approach (e.g., psychological, social, and spiritual). Wellness is referred to in terms of people's satisfaction and their quality of life. Furthermore, most available studies regarding the challenges faced by healthcare providers address some of the most frequently identified problems that are, in part, related to the concept of wellness.

Among the psychosocial and emotional problems that healthcare workers face, burnout has been identified as a three-dimensional construct, involving emotional exhaustion, depersonalization, and reduction of personal achievement as a result of chronic emotional and interpersonal stress at work [14]. Burnout often appears during the formative years for students in various health professions, including medical $[15,16]$, nursing [17], dental, and dental hygiene [18], and continues once their careers have been initiated and established. In particular, the prevalence of burnout remains high in pharmacists [19], medical residents [20], nurses [21], and established physicians. Approximately $50 \%$ of students already suffer from burnout before starting a medical residency [22]. Burnout rates are similar in the nursing field [23], with dental and dental hygiene students displaying burnout rates of around $40 \%$ [18], and $68 \%$ of pharmacists report job stress and overwork [24]. Among health professionals, only established dentists have reported considerably lower burnout rates, approximately in the range of $13 \%$ [25].

Although burnout is not considered a mental health illness per se, it has been associated with well-documented diagnoses of mental health disease and its effects. Notably, about $90 \%$ of people with burnout syndrome test positive for depression [26]. Burnout and depression are so closely linked that reviewing these two occurrences has raised questions about whether they are separate entities or, rather, if burnout is a type of depression [27]. This connection is evident even in the undergraduate years, where pre-med students have a higher prevalence of emotional burnout and a higher degree of depression compared to other undergraduates [28]. Studies further suggest that the prevalence of depression and anxiety among medical students is higher than in the general population and among their peers [29]. In addition, perceived stress and the number of students at risk for depression increase significantly from the beginning of medical school with respect to third-year students [30]. This trend continues in residency where the rate of depression increases significantly in the first months of an internal medicine internship [31]. Critically, the negative impact of burnout on professional performance has been well demonstrated. In particular, burnout has often been associated with incidents of patient insecurity, poorer quality of care due to lack of professionalism, decreased patient satisfaction [32], and increased absenteeism and disability [33]. Given the close relationship between burnout and depression, it is therefore not surprising that physicians with a positive diagnosis of depression also have a higher rate of medical error and deteriorated health [34].

Prolonged stress during medical school is reflected not only in increased rates of burnout and depression but also in high rates of suicide mortality. Male and female doctors die by suicide at rates that are $40 \%$ and $130 \%$ higher, respectively, than the general population [35]. This exceptionally high rate of suicide in female medical practitioners is likely explained by their high initial rates of depression combined with an increased frequency of successful suicide attempts relative to other women. Data on suicide rates for other health workers, including nurses and dentists, are scarce [36], and a similar problem exists for suicide rates among medical students [37]. Perhaps surprisingly, physicians and medical students are reluctant to seek treatment for mental illness, usually due to fear of documentation in their medical records and the negative impact this could have on their professional licensing [38, 39]. Post-mortem toxicology analysis has demonstrated that physicians often lack evidence of treatment for psychiatric illness at the time of suicide [40].

In 2017, the Accreditation Council for Graduate Medical Education (ACGME) in the USA revised residency and fellowship requirements to "emphasize that psychological, emotional, and physical well-being are critical to the development of a competent, caring, and resilient physician." In addition, the ACGME launched a series of web-based wellness resources, including videos, a mobile app, and podcasts [41]. Other professional societies, including the American Association of Colleges of Pharmacy (AACP) and the American Dental Students Association (ASDA), have made similar statements to encourage development of wellness education during training [42-44].

However, to date, there is no comprehensive wellness program for residents and medical students, only independent modules.

In this study, we focused on the concept of wellness instead of well-being based on the Indivisible Self model [45]. This wellness concept uses a holistic approach and is the only evidence-based model of wellness used in counseling. We hypothesized that an intervention using this holistic approach could improve self-assessment related to quality of life (wellness) and reduce long-term fatigue in health science students.

With respect to the Indivisible Self model, different authors identified and presented empirical correlations related to health, quality of life, and longevity, as used in the Wheel of Wellness model, after reviewing scientific evidence from multiple disciplines [46-48]. The Lifestyle Assessment Scale [49] 
was used to test the relationships proposed by the Wheel of Wellness model. The Lifestyle Assessment Scale did not support the expected relationships between the aforementioned factors; however, Myers and Sweeney identified five second-order factors (the Creative Self, the Confrontational Self, the Social Self, the Essential Self, and the Physical Self [50]) and a higher-order one-dimensional factor called wellness, by applying exploratory and confirmatory factor analysis. This new model provided insight into the multidimensional nature of wellness and its holistic function [51].

In this study, we presented concepts corresponding to each one of the five second-order factors of the model during a workshop. In order to determine any difference in scores, we assessed metrics of physical and emotional quality of life in health students who completed this comprehensive program which postulates that wellness is present when all physical, emotional, and spiritual components are intertwined as an integral part of the individual's wellness [52]. Two scales were used to determine pre- and post-measures of quality of life, and prolonged fatigue among health students before and after attending this comprehensive program, as well as for controls who did not attend.

\section{Methods and Materials}

\section{Type of Study}

This study is a pre-post descriptive intervention.

\section{Participants}

The sample included 96 (87.3\%) cases (attendees) out of 110 students from different health disciplines at the Institute of Biomedical Sciences of the Autonomous University of Ciudad Juarez, Mexico, who participated in a support program for students at risk of dropping out of the COBE program (Programa de Orientación y Bienestar Estudiantil). A group of 39 students from the same institute who did not attend the workshop was used as the control. This group of students were enrolled in a previous semester in the COBE program and agreed to participate before resuming their regular courses and completed the Quality of Life and Chronic Fatigue scales twice.

\section{Procedure}

All COBE attendees were at-risk students who participated in a 4-h workshop that was conducted in two sessions, lasting $2 \mathrm{~h}$ each, with each session separated by 1 week. Students entered the COBE program upon failing two classes in a single semester. In the subsequent semester, the students were placed on probation in the COBE program and did not enroll in regular coursework. At the end of the semester, if they were still in the COBE program, which involved the development of study habit skills and other activities, such as sports, they were eligible to enroll in regular coursework. Furthermore, this was the first time our wellness program was included in the COBE program, and the results of such inclusion are presented herein. Health science students completed the Quality of Life and Chronic Fatigue scales before and after the workshop. Only students who completed both sessions of the program were included in the results. Individuals in the control group also responded to the scales two times, 1 week apart, but did not attend the workshop.

The main components incorporated into the workshop are derived from the Indivisible Self model [52] and have been previously assessed for their ability to promote well-being among mid-level managers [53]. For healthcare providers, we made contextual adaptations and incorporated additional components, including resilience, emotional awareness, optimism, and relaxation. The second-order factors of the Indivisible Self- the Essential Self, the Creative Self, the Coping Self, the Social Self, and the Physical Self [52] - are the guidelines for presenting the material. Highly structured presentations for each section were given to small groups of 15 to 18 students: these included video clips and exercises corresponding to each of the sections. During the workshop, the holistic approach to wellness was emphasized in order to continuously reinforce the idea that these components should be considered integrated and constitute a philosophy of life.

\section{Measurements}

\section{Quality of Life}

The WHOQOL-BREF is an abbreviated generic Quality of Life Scale developed through the World Health Organization. It is a self-administered instrument that consists of 26 questions (Q), distributed in four dimensions: physical health, psychological health, social relations, and environment [54].

It is a brief version of an original instrument containing 100 questions. Examples of questions included in the instrument were Q5: How much do you enjoy life? and Q6: To what extent do you feel your life to be meaningful? Additionally, the dimensions included questions about events and experiences that occurred in the last 2 weeks with five options for responses on a Likert scale ranging from $1=$ Not at all, $2=\mathrm{A}$ little, $3=$ A moderate amount, $4=$ Very much, and $5=\mathrm{An}$ extreme amount. This scale has reported adequate psychometric properties for both the English and Spanish versions, with a Cronbach alpha score $>70[54,55]$. 
The scores were calculated by reversing three negatively framed questions (Q3, Q4, and Q26) to positively framed questions by reversing the Likert scale scores, where $1=5$, $2=4,3=3,4=2$, and $5=1$. Physical health was calculated by the mean reported scores of Q3, Q4, Q10, Q15, Q16, Q17, and Q18, and multiplied by 4 . The scores were multiplied by 4 to make them comparable with scores derived from the WHOQOL-100. Psychological health was calculated by the mean reported scores of Q5, Q6, Q7, Q11, Q19, and Q26. Social relations were calculated by the mean reported scores of Q20, Q21, and Q22. Finally, environment was calculated by the mean reported scores of Q8, Q9, Q12, Q13, Q14, Q23, Q24, and Q25. An increase in the scores from T1 (before the workshop) to T2 (at the end of workshop) indicated an improvement in the Quality of life factors.

\section{Fatigue}

The Multidimensional Fatigue Inventory (MFI-20), which was adapted from Spanish to Mexican Spanish, was used to measure prolonged fatigue. The MFI-20 is a self-administered instrument that consists of 20 questions and is divided into five dimensions: general fatigue, physical fatigue, reduced motivation, reduced activity, and mental fatigue [56]. Each contains four items that are responded to in a 5-point scale that ranged from 1 (yes, that is true) to 5 (no, that is not true).

Factors were calculated by adding the reported scores for each of the factors. A reduction in the scores indicated a reduction in the fatigue scores.

Examples of question scoring are as follows: General fatigue $=\mathrm{q} 1+\mathrm{q} 5+\mathrm{q} 12+\mathrm{q} 16$, Physical fatigue $=\mathrm{q} 2+\mathrm{q} 8+\mathrm{q} 14$ $+\mathrm{q} 20$, Reduced activity $=\mathrm{q} 3+\mathrm{q} 6 \mathrm{q} 10+\mathrm{q} 17$, Reduced motivation $=\mathrm{q} 4+\mathrm{q} 9+\mathrm{q} 15+\mathrm{q} 18$, and Mental fatigue $=\mathrm{q} 7+\mathrm{q} 11+$ $\mathrm{q} 13+\mathrm{q} 19$.

Examples of questions included in General fatigue factor ("I feel tired."), Physical fatigue ("Physically, I only feel able to do a little).

\section{Data Analysis}

The effect of the wellness intervention on pre- and post-test scores was determined using paired-sample $t$ tests comparing the factors corresponding to quality of life, and prolonged fatigue. IBM SPSS v. 22.0 software was used for all statistical analysis. This study was approved by the University of Ciudad Juarez Bioethics Committee and Data Analysis to the TTUHSC Institutional Review Board.

\section{Results}

Demographic information for both the attendee and control groups are presented in the Table 1. Both groups included a
Table 1 Demographic information for attendees and controls

\begin{tabular}{lll}
\hline & $\begin{array}{l}\text { Attendees } \\
n=96\end{array}$ & $\begin{array}{l}\text { Controls } \\
n=34\end{array}$ \\
\hline Gender & $n(\%)$ & $n(\%)$ \\
Male & $57(59.40)$ & $20(58.80)$ \\
Female & $39(40.60)$ & $14(41.20)$ \\
Age, mean (SD) & $24.41(3.11)$ & $25.47(3.75)$ \\
Areas of study & $n(\%)$ & $n(\%)$ \\
Biology & $9(9.40)$ & $3(8.80)$ \\
Dentistry & $12(12.50)$ & $5(14.70)$ \\
Medicine & $21(21.90)$ & $7(20.60)$ \\
Nursing & $4(4.20)$ & $2(5.90)$ \\
Nutrition & $8(8.30)$ & $3(8.80)$ \\
Pharmacy & $9(9.40)$ & $3(8.80)$ \\
Sports Medicine & $18(18.80)$ & $6(17.60)$ \\
Veterinary & $15(15.60)$ & $5(14.70)$ \\
\hline
\end{tabular}

larger percentage of males than females. A similar distribution of areas of study was present in both populations, with the largest percentage of student in Medicine, followed by Sports Medicine.

Pre-intervention, there were no significant differences between attendees and controls in regard to scores for subscales measuring quality of life, and prolonged fatigue.

Quality of life scores before the wellness intervention at T1 and after the intervention at $\mathrm{T} 2$ are presented in Table 2. In the attendee group, those who attended the workshop, the scores at $\mathrm{T} 2$ were significantly higher compared with those at $\mathrm{T} 1$, with a significance of $P<0.0001$. These results indicated an improvement in the QOL domains. In contrast, there were no significant differences in the scores at $\mathrm{T} 1$ and $\mathrm{T} 2$ in the control group (Table 2).

The scores for most of the fatigue subscales showed a significant reduction at $\mathrm{T} 2$ versus $\mathrm{T} 1 \mathrm{in}$ the attendee group, which for this scale indicated an improvement (Table 3). The only exception is the concentration subscale, for which there was a reduction, albeit not significant.

\section{Discussion}

The results of this study indicate that in the short term, there was an improvement in self-perception of quality of life, and prolonged fatigue in a group of healthcare students who attended our wellness workshop that emphasizes a holistic approach to wellness. This workshop was specifically designed to benefit health sector students in key areas, thereby strengthening their capacity to meet the challenges they face today, as well as those they might face in the future.

Medical education institutions at the undergraduate level have implemented various wellness programs for students in 
Table 2 Quality of life subscales mean scores prior to (T1) and following (T2) intervention

\begin{tabular}{|c|c|c|c|c|c|c|}
\hline \multirow{2}{*}{$\begin{array}{l}\text { Subscales quality of life } \\
\text { Mean (DS) }\end{array}$} & \multicolumn{3}{|c|}{ Controls, $n=39$} & \multicolumn{3}{|c|}{ Attendees, $n=96$} \\
\hline & $\mathrm{T} 1$ & $\mathrm{~T} 2$ & $P$ & $\mathrm{~T} 1$ & $\mathrm{~T} 2$ & $P$ \\
\hline Physical health & $14.64(2.23)$ & $14.49(2.20)$ & 0.25 & $14.98(2.26)$ & $15.78(2.15)$ & $<0.001^{*}$ \\
\hline Psychological well-being & $13.59(3.26)$ & $13.41(3.03)$ & 0.33 & $13.17(2.76)$ & $14.72(2.61)$ & $<0.001^{*}$ \\
\hline Social relationships & $14.86(3.35)$ & $14.78(3.35)$ & 0.33 & $13.93(3.11)$ & $14.92(3.09)$ & $<0.001^{*}$ \\
\hline Environment & $14.64(2.23)$ & $14.49(2.20)$ & 0.17 & $14.26(2.16)$ & $15.10(2.24)$ & $<0.001^{*}$ \\
\hline
\end{tabular}

*Significant an attempt to mitigate the negative effects of stress on their mental health. However, these methods are not always systematically studied or implemented, nor are they comprehensive. Some methods, such as self-development groups, the Respiratory One Method for relaxation, and a conversion to a pass/fail grading system, appear to reduce burnout among undergraduate medical students [57]. Mindfulness-based interventions have also been shown to decrease stress, anxiety, and depression and to improve attention span, mood, self-efficacy, and empathy in medical, nursing, social work, and psychology students [58]. Small-scale studies have further found that mindfulness meditation has a positive impact on stress, anxiety, depression, burnout, well-being, and empathy in nurses and nursing students [59]. Internet and computerbased interventions can also be effective for improving depression, anxiety, and stress in students within the general college population [60]. Evidence further suggests that cognitive-behavioral group interventions are beneficial for the mental health of health professionals and students $[61$, 62]. In addition, curriculum changes affecting course content, scheduling, grading systems, and restriction of hours of service have also been shown to improve the mental health of medical students and residents [63-65].

The pressures faced by healthcare providers as a result of the COVID-19 pandemic reveal the urgent need for validated programs aimed at mitigating stress and promoting wellness and mental health among these individuals. In particular, comprehensive programs that facilitate the development and enhancement of their regular capabilities, as well as extraordinary capabilities that will be needed to address public health challenges both currently and in the future, are needed. Such programs should focus on strengthening these professionals by promoting their physical, emotional, and spiritual health. Although attempts have been made to create such wellness programs, they are usually specific to a specialty or institution [10, 66-68]. Extending these initiatives, especially into the curriculum, may provide better tools for health professionals and should be considered now more than ever as part of all healthcare training programs.

This study has some limitations, including the fact that the students who completed the intervention were those at risk of dropping out of their programs, and consequently, they may have needs that are different from students not in at-risk groups. Despite the possibility that this program may not meet all of the wellness needs of students, our effort joins many others that have been implemented in the past and could be considered for the benefit of students. Lastly, despite the emphasis placed on this program becoming a lifelong learning experience, it is possible that the results obtained will be short term rather than long term, and more studies are needed determine its longterm possibilities. The mental health of the students who participated in this study was not addressed, which may be a confounding factor in the results. However, the intervention included pre- and post-measures that allow for comparison of results at two different points in time in relation to quality of life and prolonged fatigue. Despite these limitations, the positive results obtained in such a short time suggest that this strategy should be explored and further studied.
Table 3 Fatigue subscales mean scores prior to (T1) and following (T2) intervention

\begin{tabular}{llllllll}
\hline Subscales fatigue & \multicolumn{2}{l}{ Controls, $n=39$} & & & \multicolumn{2}{l}{ Attendees, $n=96$} \\
\cline { 2 - 3 } \cline { 7 - 8 } Mean (DS) & T1 & T2 & $P$ & & T1 & T2 & $P$ \\
\hline General fatigue & $12.35(3.65)$ & $12.59(2.83)$ & 0.61 & & $11.91(3.67)$ & $10.27(3.39)$ & $<0.001^{*}$ \\
Physical fatigue & $11.71(4.01)$ & $11.68(3.06)$ & 0.94 & & $10.85(3.60)$ & $9.78(3.77)$ & $0.001^{*}$ \\
Physical condition & $10.79(4.55)$ & $11.12(3.60)$ & 0.43 & & $11.17(4.38)$ & $10.13(3.83)$ & $0.002^{*}$ \\
Concentration & $8.50(3.69)$ & $8.59(3.64)$ & 0.33 & & $8.52(3.63)$ & $8.09(3.19)$ & 0.223 \\
Mental fatigue & $11.50(3.86)$ & $11.82(2.87)$ & 0.38 & & $11.40(4.49)$ & $10.71(4.36)$ & $0.014^{*}$ \\
\hline
\end{tabular}

*Significant 
There were no differences in the scores between the attendees and controls before attending the workshop; however, there were significant differences in the initial and final scores among those who attended the workshop. These results supported our initial hypothesis, in which participation in the COBE program improved quality of life scores and reduced fatigue scores. Such findings were only observed in the attendee group.

Pre-existing deficiencies in healthcare systems around the world that negatively affect the well-being of health professionals must be continually examined, amended, and improved. This will lead to substantial benefits for both these individuals and their patients and will further help to strengthen the role that health professionals play in addressing our newly emerging reality.

Funding This project did not receive any external funding. The Universidad Autonoma de Ciudad Juarez provided with internal funding to complete it.

Data Availability The datasets generated during and/or analyzed during the current study are available from the corresponding author on reasonable request.

Code Availability NA

\section{Declarations}

Ethics Approval and Consent to Participate This research project was approved as an exempt study by the IRB at UACJ. At PLFSOM, it was determined not to require IRB review since it did not meet the definition of human subject research, as the information used is not identifiable.

Consent for Publication On behalf of all authors, the corresponding author states that all author consent for publication.

Conflict of Interest The authors declare no competing interests.

\section{References}

1. Ukuhor HO. The interrelationships between antimicrobial resistance, COVID-19, past, and future pandemics. J Infect Public Health. 2020;14(1):53-60.

2. Hoiby N. Pandemics: Past, present, future. APMIS: acta pathologica, microbiologica, et immunologica scandinavica. 2020. Advance online publication. https://doi.org/10.1111/apm. 13098.

3. Contini C, Di Nuzzo M, Barp N, Bonazza A, De Giorgio R, Tognon M, Rubino S. The novel zoonotic COVID-19 pandemic: an expected global health concern. J Infect Dev Ctries. 2020;14(03):254-64. https://doi.org/10.3855/jidc. 12671.

4. Zuzelo PR. Making do during a pandemic: morally distressing and injurious events. Holist Nurs Pract. 2020;34(4):259-61.

5. Szram J, Vaux E. Pandemic times: learning well in a time of COVID-19. Future Healthc J. 2020;7(2):100-1.
6. Dost B, Koksal E, Terzi O, Bilgin S, Ustun YB, Arslan HN. Attitudes of anesthesiology specialists and residents toward patients infected with the novel coronavirus (COVID-19): a national survey study. Surg Infect. 2020;21(4):350-6.

7. Jimenez-Rodriguez D, Santillan Garcia A, Montoro Robles J, Rodriguez Salvador M, Munoz Ronda FJ, Arrogante O. Increase in video consultations during the COVID-19 pandemic: healthcare professionals' perceptions about their implementation and adequate management. Int J Environ Res. 2020;17(14):5112. https://doi.org/ 10.3390/ijerph17145112.

8. Thomaier L, Teoh D, Jewett P, Beckwith H, Parsons H, Yuan J, et al. Emotional health concerns of oncology physicians in the United States: fallout during the COVID-19 pandemic. PLoS One. 2020;15(11):e0242767.

9. Wu AW, Connors C, Everly GS Jr. COVID-19: peer support and crisis communication strategies to promote institutional resilience. Ann Intern Med. 2020;172(12):822-3.

10. Drolet BC, Rodgers S. A comprehensive medical student wellness program-design and implementation at Vanderbilt School of Medicine. Acad Med. 2010;85(1):103-10.

11. Blake H, Yildirim M, Wood B, Knowles S, Mancini H, Coyne E, et al. COVID-Well: evaluation of the implementation of supported wellbeing centres for hospital employees during the COVID-19 pandemic. Int J Environ Res Public Health. 2020;17(24):9401. https://doi.org/10.3390/ ijerph17249401.

12. Ceri V, Cicek I. Psychological well-being, depression and stress during COVID-19 pandemic in Turkey: a comparative study of healthcare professionals and non-healthcare professionals. Psychol Health Med. 2021;26(1):85-97. https://doi.org/10.1080/13548506. 2020.1859566.

13. Esteban-Gonzalo S, Gonzalez-Pascual JL, Caballero-Galilea M, Esteban-Gonzalo L. Psychosocial correlates of mental health and well-being during the COVID-19: the Spanish case. Front Psychol. 2020;11:609815.

14. Maslach C, Schaufeli WB, Leiter MP. Job burnout. Annu Rev Psychol. 2001;52(1):397-422.

15. Dyrbye LN, West CP, Satele D, Boone S, Tan L, Sloan J, et al. Burnout among U.S. medical students, residents, and early career physicians relative to the general U.S. population. Acad Med. 2014;89(3):443-51.

16. Hope V, Henderson M. Medical student depression, anxiety and distress outside North America: a systematic review. Med Educ. 2014;48(10):963-79.

17. Rudman A, Gustavsson JP. Early-career burnout among new graduate nurses: A prospective observational study of intraindividual change trajectories. Int J Nurs Stud. 2011;48(3): 292-306.

18. Deeb GR, Braun S, Carrico C, Kinser P, Laskin D, Golob DJ. Burnout, depression and suicidal ideation in dental and dental hygiene students. Eur J Dent Educ. 2018;22(1):e70-e4.

19. Durham ME, Bush PW, Ball AM. Evidence of burnout in healthsystem pharmacists. Am J Health Syst Pharm. 2018;75(23 Supplement 4):S93-s100.

20. Rodrigues H, Cobucci R, Oliveira A, Cabral JV, Medeiros L, Gurgel K, et al. Burnout syndrome among medical residents: a systematic review and meta-analysis. PLoS One. 2018;13(11): e0206840.

21. Friganovic A, Selic P, Ilic B, Sedic B. Stress and burnout syndrome and their associations with coping and job satisfaction in critical care nurses: a literature review. Psychiatr Danub. 2019;31(Suppl 1):21-31.

22. Frajerman A, Morvan Y, Krebs MO, Gorwood P, Chaumette B. Burnout in medical students before residency: a systematic review and meta-analysis. Eur Psychiatry. 2019;55:36-42. 
23. Zhang YY, Han WL, Qin W, Yin HX, Zhang CF, Kong C, et al. Extent of compassion satisfaction, compassion fatigue and burnout in nursing: a meta-analysis. J Nurs Manag. 2018;26(7):810-9.

24. Mott DA, Doucette WR, Gaither CA, Pedersen CA, Schommer JC. Pharmacists' attitudes toward worklife: results from a national survey of pharmacists. J Am Pharm Assoc (2003). 2004;44(3):326-36.

25. Calvo JM, Kwatra J, Yansane A, Tokede O, Gorter RC, Kalenderian E. Burnout and work engagement among US dentists. J Patient Saf. 2017. Advance online publication. https://doi.org/10. 1097/PTS.0000000000000355.

26. Bianchi R, Schonfeld IS, Laurent E. Is burnout a depressive disorder? A reexamination with special focus on atypical depression. Int J Stress Manag. 2014;21(4):307.

27. Bianchi R, Schonfeld IS, Laurent E. Burnout-depression overlap: a review. Clin Psychol Rev. 2015;36:28-41.

28. Fang DZ, Young CB, Golshan S, Moutier C, Zisook S. Burnout in premedical undergraduate students. Acad Psychiatry. 2012;36(1): $11-6$.

29. Dyrbye LN, Thomas MR, Shanafelt TD. Systematic review of depression, anxiety, and other indicators of psychological distress among U.S. and Canadian medical students. Acad Med. 2006;81(4):354-73.

30. Ludwig AB, Burton W, Weingarten J, Milan F, Myers DC, Kligler B. Depression and stress amongst undergraduate medical students. BMC Med Educ. 2015;15:141.

31. Pereira-Lima K, Gupta RR, Guille C, Sen S. Residency program factors associated with depressive symptoms in internal medicine interns: a prospective cohort study. Acad Med. 2019;94(6):86975.

32. Panagioti M, Geraghty K, Johnson J, Zhou A, Panagopoulou E, Chew-Graham C, et al. Association between physician burnout and patient safety, professionalism, and patient satisfaction: a systematic review and meta-analysis. JAMA Intern Med. 2018;178(10):1317-30.

33. Regehr C, Glancy D, Pitts A, LeBlanc VR. Interventions to reduce the consequences of stress in physicians: a review and meta-analysis. J Nerv Ment Dis. 2014;202(5):353-9.

34. Pereira-Lima K, Mata DA, Loureiro SR, Crippa JA, Bolsoni LM, Sen S. Association between physician depressive symptoms and medical errors: a systematic review and meta-analysis. JAMA Netw Open. 2019;2(11):e1916097.

35. Schernhammer E. Taking their own lives - the high rate of physician suicide. N Engl J Med. 2005;352(24):2473-6.

36. Dutheil F, Aubert C, Pereira B, Dambrun M, Moustafa F, Mermillod M, et al. Suicide among physicians and health-care workers: a systematic review and meta-analysis. PLoS One. 2019;14(12):e0226361.

37. Blacker CJ, Lewis CP, Swintak CC, Bostwick JM, Rackley SJ. Medical student suicide rates: a systematic review of the historical and international literature. Acad Med. 2019;94(2):274-80.

38. Knipe D, Maughan C, Gilbert J, Dymock D, Moran P, Gunnell D. Mental health in medical, dentistry and veterinary students: crosssectional online survey. BJ Psych Open. 2018;4(6):441-6.

39. Dyrbye LN, West CP, Sinsky CA, Goeders LE, Satele DV, Shanafelt TD. Medical licensure questions and physician reluctance to seek care for mental health conditions. Mayo Clin Proc. 2017;92(10):1486-93.

40. Gold KJ, Sen A, Schwenk TL. Details on suicide among US physicians: data from the National Violent Death Reporting System. Gen Hosp Psychiatry. 2013;35(1):45-9.

41. Improving physician well-being, restoring meaning in medicine: Accreditation Council for Graduate Medical Education 2020 [Available from: https://www.acgme.org/What-We-Do/Initiatives/ Physician-Well-Being.]
42. Health and wellness: ASDA; 2018.

43. Wel wellness and resilience in pharmacy educationlness and resilience in pharmacy education: AACP; 2020 [Available from: https:// www.aacp.org/resource/wellness-and-resilience-pharmacyeducation].

44. Wellness and resilience in pharmacy education and resilience in pharmacy education: AACP; 2020 [Available from: https:/www. aacp.org/resource/wellness-and-resilience-pharmacy-education].

45. Myers JE, Sweeney TJ. The indivisible self: an evidence-based model of welIness (reprint). J Individ Psychol. 2005;61(3):269-79.

46. Myers JE, Sweeney TJ, Witmer JM. The wheel of wellness counseling for wellness: a holistic model for treatment planning. J Couns Dev. 2000;78(3):251-6.

47. Witmer JM, Sweeney TJ. A holistic model for wellness and prevention over the life span. J Couns Dev. 1992;71(2):140-8.

48. Sweeney TJ, Witmer JM. Beyond social interest: striving toward optimum health and wellness. Indiv Psychol. 1991;47(4) 527(4): 527-40.

49. Myers JE, Witmer JM, Sweeney TJ. Manual for the wellness evaluation of lifestyle: Mind Garden, Incorporated; 2004.

50. Hattie JA, Myers JE, Sweeney TJ. A factor structure of wellness: theory, assessment, analysis, and practice. J Couns Dev. 2004;3: 354.

51. Myers JE, Sweeney TJ. The Indivisible Self: an evidence-based model of wellness. J Individ Psychol. 2004;60:234-44.

52. Myers JE, Sweeney TJ. Wellness counseling: The evidence base for practice. J Couns Dev. 2008;86(4):482-93.

53. Medina MDC, Calderon A, Blunk DI, Mills BW, Leiner M. Organizational wellness program implementation and evaluation: a holistic approach to improve the wellbeing of middle managers. J Occup Environ Med. 2018;60(6):515-20.

54. Group W. Measuring quality of life. Geneva: The World Health Organization; 1997. p. 1-13.

55. Lucas-Carrasco R. The WHO quality of life (WHOQOL) questionnaire: Spanish development and validation studies. Qual Life Res. 2012;21(1):161-5.

56. Smets EM, Garssen B, Bonke B, De Haes JC. The Multidimensional Fatigue Inventory (MFI) psychometric qualities of an instrument to assess fatigue. J Psychosom Res. 1995;39(3): 315-25.

57. Williams D, Tricomi G, Gupta J, Janise A. Efficacy of burnout interventions in the medical education pipeline. Academic psychiatry: the journal of the American Association of Directors of Psychiatric Residency Training and the Association for Academic Psychiatry. 2015;39(1):47-54. https://doi.org/10.1007/s40596014-0197-5.

58. McConville J, McAleer R, Hahne A. Mindfulness training for health profession students-the effect of mindfulness training on psychological well-being, learning and clinical performance of health professional students: a systematic review of randomized and non-randomized controlled trials. Explore (NY). 2017;13(1): 26-45.

59. van der Riet P, Levett-Jones T, Aquino-Russell C. The effectiveness of mindfulness meditation for nurses and nursing students: an integrated literature review. Nurse Educ Today. 2018;65:201-11.

60. Davies EB, Morriss R, Glazebrook C. Computer-delivered and web-based interventions to improve depression, anxiety, and psychological well-being of university students: a systematic review and meta-analysis. J Med Internet Res. 2014;16(5):e130.

61. Lo K, Waterland J, Todd P, Gupta T, Bearman M, Hassed C, et al. Group interventions to promote mental health in health professional education: a systematic review and meta-analysis of randomised controlled trials. Adv Health Sci Educ Theory Pract. 2018;23(2): 413-47. 
62. Ruotsalainen JH, Verbeek JH, Marine A, Serra C. Preventing occupational stress in healthcare workers. Cochrane Database Syst Rev. 2014;12:Cd002892.

63. Slavin SJ, Schindler DL, Chibnall JT. Medical student mental health 3.0: improving student wellness through curricular changes. Acad Med. 2014;89(4):573-7.

64. Moeller A, Webber J, Epstein I. Resident duty hour modification affects perceptions in medical education, general wellness, and ability to provide patient care. BMC Med Educ. 2016;16:175.

65. Buchholz AL, Henderson F Jr, Lowe S, Alshareef M, Wolgamott L, Patel S, et al. Perspectives from a residency training program following the implementation of a wellness initiative. World Neurosurg. 2018;119:e947-e55.

66. Zaver F, Battaglioli N, Denq W, Messman A, Chung A, Lin M, et al. Identifying gaps and launching resident wellness initiatives: the 2017 Resident Wellness Consensus Summit. West J Emerg Med. 2018;19(2):342-5.

67. A strategy for maintaining student wellbeing: Nursing Times; 2015 [Available from: https://www.nursingtimes.net/roles/mentalhealth-nurses/a-strategy-for-maintaining-student-wellbeing-09-022015/.]

68. Uclahealth.org. Wellness Initiative-UCLA Internal Medicine Residency Program 2019 [Available from: https://www. uclahealth.org/im-residency/wellness-initiative.]

Publisher's note Springer Nature remains neutral with regard to jurisdictional claims in published maps and institutional affiliations. 